\title{
O nutricionista no Brasil: uma análise histórica'
}

\section{The nutritionist in Brazil: a historical analysis}

Francisco de Assis Guedes de VASCONCELOS²

RESUMO

O objetivo deste artigo foi realizar uma análise histórica do processo de emergência e evolução da profissão de nutricionista no Brasil. A metodologia utilizada baseou-se principalmente em revisão da literatura sobre a história da Nutrição no Brasil no período de 1939 a 2000. Como critérios metodológicos de análise foram estabelecidos quatro cortes transversais, correspondentes a contextos específicos da história deste profissional: 1939-1949, 1950-1975, 1976-1984, 1985-2000. Por fim, o artigo procura apontar as perspectivas imediatas e mediatas que podem ser visualizadas para a prática profissional do nutricionista no decorrer do século XXI.

Termos de indexação: história da nutrição, nutricionista, ocupações em saúde.

\section{A B S TR ACT}

The objective of this article was to carry out a historical analysis of the process that established the origin and the evolution of the nutritionist in Brazil. The methodology was based on a literature review of the history of Nutrition in Brazil from 1939 to 2000. As methodological criteria of analysis four transverse sections were established, corresponding to specific contexts of the history of this professional: 1939-1949, 1950-1975, 1976-1984, 1985-2000. Finally, the article tries to point out the mediate and immediate perspectives that can be visualized for the professional practice of the nutritionist during the $X X I$ century.

Index terms: history of nutrition, nutritionist, health occupations.

\footnotetext{
1 Trabalho elaborado a partir da tese de doutorado em Saúde Pública de F.A.G. VASCONCELOS "Como nasceram os meus anjos brancos: a constituição do campo da Nutrição em Saúde Pública em Pernambuco". Escola Nacional de Saúde Pública, Fundação Oswaldo Cruz, 1999. 266p.

2 Departamento de Nutrição, Centro de Ciências da Saúde, Universidade Federal de Santa Catarina. Campus Universitário, Trindade, 88040-900, Florianópolis, SC, Brasil.E-mail: fguedes@floripa.com.br
} 


\section{N T R O D U Ç Ã O}

No cenário mundial, a emergência do campo da Nutrição, seja como ciência, política social e/ou profissão, é um fenômeno relativamente recente, característico do início do século XX. Entretanto, é possível sustentar que as condições históricas para a constituição deste campo científico, acumuladas ao longo da história da humanidade, foram estimuladas a partir da revolução industrial européia, ocorrida no século XVIII, e desencadearam-se entre 1914 e 1918, quando ocorreu a Primeira Guerra Mundial. Neste sentido, no período entre as duas Guerras Mundiais, tanto em países da Europa (Inglaterra, França, Itália, Alemanha, Dinamarca, entre outros), como da América do Norte (Estados Unidos e Canadá) e, posteriormente, da América Latina (Argentina e Brasil), foram criados os primeiros centros de estudos e pesquisas, os primeiros cursos para formação de profissionais especialistas e as primeiras agências condutoras de medidas de intervenção em Nutrição (Maurício, 1964; Coimbra et al., 1982; L'Abbate, 1988; Associação..., 1991; Vasconcelos, 1999b).

Na América Latina, a emergência da Nutrição foi fortemente influenciada pelo médico argentino Pedro Escudero, criador do Instituto Nacional de Nutrição em 1926, da Escola Nacional de Dietistas em 1933 e do curso de médicos "dietólogos" da Universidade de Buenos Aires. As concepções de Escudero sobre este campo do saber foram difundidas em toda a América Latina, em função, inclusive, da concessão anual a cada país latino-americano de bolsas de estudos para a realização de Cursos de Dietética no referido instituto. Assim, entre os primeiros brasileiros a estagiarem ou realizarem cursos promovidos por Escudero na Argentina, destacamos: José João Barbosa e Sylvio Soares de Mendonça (curso de dietólogos); Firmina Sant'Anna e Lieselotte Hoeschl Ornellas (curso de dietistas) e Josué de Castro, o qual realizou um estágio (Coimbra et al., 1982; L'Abbate, 1988; Associação..., 1991; Icaza, 1991).
No Brasil, segundo apontam alguns estudos, a Nutrição teria emergido no decorrer dos anos 1930-1940, como parte integrante do projeto de modernização da economia brasileira, conduzido pelo chamado Estado Nacional Populista, cujo contexto histórico delimitou a implantação das bases para a consolidação de uma sociedade capitalista urbano-industrial no país (Coimbra et al., 1982; L'Abbate, 1988; Vasconcelos, 1988; Lima, 1997; Magalhães, 1997).

Entretanto, é preciso registrar que, desde a segunda metade do século XIX, o saber sobre a alimentação da população brasileira começou a despontar de forma mais sistematizada, dentro do campo do conhecimento médico, através das teses apresentadas às duas faculdades de Medicina (Bahia e Rio de Janeiro) existentes até então no país. Portanto, são um pouco divergentes os marcos emergenciais da Nutrição brasileira, conforme a literatura pesquisada. Alguns autores mencionam o livro de Eduardo Magalhães, Higiene Alimentar, publicado em 1908, outros, os estudos desenvolvidos, a partir de 1906, por Álvaro Osório de Almeida no campo da Fisiologia da Alimentação. Contudo, a existência de pesquisas anteriores a respeito de doenças carenciais relacionadas à alimentação e de hábitos alimentares da população brasileira, tais como aqueles desenvolvidos pelos médicos Gama Lobo sobre "avitaminose A" e Nina Rodrigues sobre o consumo de farinha de mandioca, atestam ser bem mais remoto o interesse por esta temática (Maurício, 1964; Coimbra et al., 1982; L' Abbate, 1988; Martins, 1994; Freyre, 1998).

De acordo com Maurício (1964), Coimbra et al. (1982) e L'Abbate (1988), nos primeiros anos da década de 1930, tanto no Rio de Janeiro como em São Paulo e, posteriormente, em Salvador e no Recife, duas correntes bem definidas e distintas do saber médico confluíram para a constituição do campo da Nutrição. De um lado encontravam-se os partidários da corrente que chamamos de perspectiva biológica, preocupados essencialmente com aspectos clínico- 
-fisiológicos relacionados ao consumo e à utilização biológica dos nutrientes e influenciados por concepções das Escolas de Nutrição e Dietética norte-americanas e de centros europeus. Entre estes médicos integrantes do núcleo inicial da perspectiva biológica da Nutrição, cuja atuação era voltada para o individual, o doente, a clínica, a fisiologia e o laboratório, são citados: Franklin de Moura Campos, Paulo Santos, Dutra de Oliveira, Hélio Lourenço de Oliveira, Silva Mello, Olavo Rocha, Alexandre Moscoso, Salvio de Souza Mendonça e Salgado Filho. A partir de 1940, esta vertente deu origem à Nutrição Clínica (Dietoterapia), considerada a especialização matriz do campo da Nutrição dentro do contexto mundial, direcionada para a prática de ações, de caráter individual, centradas no "alimento como agente de tratamento" (Ypiranga \& Gil, 1989), bem como originou a Nutrição Básica e Experimental, uma outra especialização, voltada ao desenvolvimento de pesquisas básicas de caráter experimental e laboratorial. De outro lado encontravam-se os adeptos das idéias da corrente que chamamos de perspectiva social, preocupados particularmente com aspectos relacionados à produção, à distribuição e ao consumo de alimentos pela população brasileira e influenciados, principalmente, pelas concepções do pioneiro da Nutrição na América Latina, Pedro Escudero. Entre estes médicos integrantes do núcleo inicial da perspectiva social da Nutrição, cuja atuação era voltada para o coletivo, a população, a sociedade, a economia e a disponibilidade de alimentos, são citados: Heitor Annes Dias, Josué de Castro, Dante Costa, Thales de Azevedo, Peregrino Júnior, Seabra Velloso e Silva Telles. A partir da década de 1940, esta vertente deu origem à Alimentação Institucional (Alimentação Coletiva), também considerada como uma especialização matriz do campo da Nutrição, direcionada para a "administração no sentido de racionalização da alimentação" (Ypiranga \& Gil, 1989) de coletividades sadias e enfermas, bem como, nos anos 1950-1960, originou a Nutrição em Saúde Pública, uma outra especialização, voltada ao desenvolvimento de ações de caráter coletivo " no sentido de contribuir para garantir que a produção e distribuição de alimentos seja adequada e acessível a todos os indivíduos da sociedade" (Ypiranga \& Gil, 1989).

Apesar de, hegemonicamente, centralizar-se nestes dois principais pólos urbano-industriais do país, a existência de pesquisas sobre as condições nutricionais da população brasileira fora deste eixo central indica a descentralização deste processo para outros estados. No caso particular de Pernambuco, observa-se que, a partir dos primeiros anos da década de 1930, um considerável conjunto de estudos começou a ser desenvolvido por importantes intelectuais envolvidos na história da constituição do campo da Nutrição brasileira, entre os quais destacamos: Gilberto Freyre, Jamesson Ferreira Lima, Josué de Castro, Naíde Regueira Teodósio, Nelson Chaves, Orlando Parahym e Ruy Coutinho. Assim, por exemplo, em 1932, sob a influência de Escudero, Josué de Castro realizava a pesquisa As Condições de Vida das Classes Operárias no Recife, uma investigação baseada na metodologia de orçamento e padrão de consumo alimentar entre quinhentas famílias de três bairros operários desta cidade. Os resultados deste trabalho, considerado o primeiro inquérito dietético-nutricional do Brasil, tiveram ampla divulgação nacional, provocando a realização de estudos similares, inclusive daquele que serviu de base para a regulamentação da lei do salário mínimo e da formulação da chamada ração essencial mínima, estabelecida por intermédio do Decreto-Lei no 399, de 30 de abril de 1938. Por outro lado, em 1933, o sociólogo Gilberto Freyre, o único não vinculado às correntes de médicos nutrólogos emergentes neste período, publicava o seu clássico Casa-Grande \& Senzala, até então, o primeiro e mais completo ensaio sociológico sobre o padrão e os hábitos alimentares da sociedade brasileira. Enquanto isso, também em 1932, Nelson Chaves, publicava seus primeiros artigos científicos nos campos da Endocrinologia e Fisiologia Nutricional (Vasconcelos, 1999b).

Em síntese, ao longo da década de 1930, estas duas vertentes se uniram no processo de 
consolidação do campo da Nutrição no Brasil. Estes primeiros nutrólogos brasileiros logo iniciaram o processo de produção e difusão de estudos e pesquisas sobre composição química e valor nutricional de alimentos nacionais, sobre consumo e hábitos alimentares e sobre o estado nutricional da população brasileira, procurando, desta maneira, garantir especificidade e legitimidade para esta nova área do saber científico que se constituía no país. Da mesma forma, sobretudo a partir da segunda metade dos anos 1930, passaram a evidenciar uma certa organicidade intelectual com o chamado Estado Populista, contribuindo para a formulação das primeiras medidas e instrumentos da Política Social de Alimentação e Nutrição, os quais começavam a ser implantados no Brasil. Simultaneamente, trataram de criar os mecanismos e espaços institucionais necessários à formação dos seus novos agentes, seja através de estágios, viagens de estudos ou cursos realizados no exterior, seja através da criação dos primeiros cursos para formação de profissionais em Alimentação e Nutrição, estabelecendo a demarcação das fronteiras definidoras dos limites de competência, de autonomia e de poder entre as distintas especialidades profissionais conformadoras do complexo e interdisciplinar campo da Nutrição que se constituía (Coimbra et al., 1982; L'Abbate, 1988; Vasconcelos, 1999b).

Neste artigo, procurou-se realizar um resgate histórico do processo de emergência e evolução da profissão de nutricionista no Brasil, com base em levantamento e revisão bibliográfica sobre esta temática. Como critérios metodológicos de análise foram estabelecidos quatro cortes transversais, correspondentes a contextos específicos da história deste profissional: 1939-1949, 1950-1975, 1976-1984, 1985-2000. Em cada um destes recortes históricos, respectivamente denominados de emergência, consolidação, evolução e reprodução ampliada, buscou-se identificar e analisar os principais eventos que delimitaram a trajetória do nutricionista brasileiro dentro deste eixo longitudinal investigado. Por fim, este trabalho procura apontar as perspectivas imediatas e mediatas que podem ser visualizadas para a prática profissional do nutricionista no decorrer do século XXI.

\section{A EMERGENCIA DA PROFISSÃO (1939-1949)}

Em relação ao processo de formação do nutricionista brasileiro, idealizado pela primeira geração de médicos nutrólogos, seu início ocorreu na década de 1940, quando foram criados os quatro primeiros cursos do país. O primeiro curso para formação de nutricionistas foi criado, em 1939, no Instituto de Higiene de São Paulo (atual Curso de Graduação em Nutrição do Departamento de Nutrição da Faculdade de Saúde Pública da Universidade de São Paulo). Em 1940, tiveram início os cursos técnicos do Serviço Central de Alimentação do Instituto de Aposentadorias e Pensões dos Industriários (IAPI), os quais deram origem, em 1943, ao Curso de Nutricionistas do Serviço de Alimentação da Previdência Social (SAPS) (atual Curso de Graduação em Nutrição da Universidade do Rio de Janeiro - UNI-RIO). Em 1944, foi criado o Curso de Nutricionistas da Escola Técnica de Assistência Social Cecy Dodsworth (atual Curso de Graduação em Nutrição da Universidade Estadual do Rio de Janeiro - UERJ). E a partir de 1948 teve início o Curso de Dietistas da Universidade do Brasil (atual Curso de Graduação em Nutrição do Instituto de Nutrição da Universidade Federal do Rio de Janeiro - UFRJ) (Costa, 1953; Maurício, 1964; Associação..., 1991).

As poucas análises realizadas sobre este processo, em seu início, apontam características históricas bastante específicas, apesar das influências externas sofridas, tanto das escolas norte-americana e européias, como principalmente da escola argentina de Pedro Escudero. Conforme relatam alguns estudos, no Brasil "o profissional surge dentro do setor saúde, tendo como objeto de trabalho a alimentação do homem no seu plano individual ou coletivo" (Ypiranga \& Gil, 1989), 
característica comum à sua origem nos demais países. Outras pesquisas, entretanto, indicam o surgimento simultâneo do nutricionista no setor de administração de serviços de alimentação do trabalhador (nos restaurantes populares do SAPS), por "vontade governamental, em momento de busca de legitimação social, constituindo-se em instrumento de alívio de tensões sociais" (Ypiranga \& Gil, 1989). Ou seja, a ênfase do processo de formação do nutricionista, neste primeiro momento, foi a capacitação de um profissional para atuação tanto em Nutrição Clínica (Dietoterapia), como em Alimentação Institucional (Alimentação Coletiva).

Uma outra característica específica deste início do processo de formação profissional foi quanto à adoção da terminologia "nutricionista" . Em primeiro lugar, destaca-se que, nesta fase inicial, o profissional era formado dentro de um curso técnico de nível médio e era chamado de dietista, a exemplo da formação e denominação verificadas nos países da Europa, EUA e Canadá. Aos poucos os cursos brasileiros foram sofrendo alterações, aproximando-se das características do curso do Instituto Nacional de Nutrição da Argentina, "formando um profissional de nível universitário, com conhecimentos específicos de Nutrição, com funções e responsabilidades próprias de atenção dietética ao indivíduo sadio ou enfermo, de forma individual ou coletiva" (Icaza, 1991). Neste sentido, para alguns autores, "no Brasil, rejeitou-se porém este conceito e o termo Dietista designa um técnico de nível médio ou Auxiliar de Nutrição" (Ypiranga \& Gil, 1989), optando-se pela denominação de "nutricionista". Tal decisão seria oficializada, internacionalmente, só em 1966, no decorrer da I Conferência sobre Adestramento de Nutricionistas-Dietistas de Saúde Pública, realizada em Caracas, na Venezuela, conforme publicação da Associação Brasileira de Nutricionistas (ABN) (Ypiranga \& Gil, 1989). Entretanto, nesta revisão bibliográfica, observou-se a utilização do termo "nutricionista" desde 1939, no decreto de criação do curso do Instituto de Higiene de São Paulo. Além disso, já em 1957, este procedimento era usual no Brasil, como pode ser observado no Regulamento do Curso de Nutricionistas do Instituto de Fisiologia e Nutrição da Faculdade de Medicina da Universidade do Recife, nos documentos sobre a organização do Curso de Nutricionistas do SAPS e no Currículo do Curso de Nutricionistas do Instituto de Nutrição da Universidade do Brasil. Em segundo lugar, é preciso destacar que no interior do campo de disputas estabelecidas no processo de constituição da Nutrição no Brasil, o termo "nutricionista", conforme pode ser observado em algumas fontes documentais da época, também foi usado como designação das primeiras gerações de médicos nutrólogos brasileiros (Vasconcelos, 1999b).

Por outro lado, de acordo com outras publicações da época, não apenas as denominações, mas também os limites de competência de cada profissional vinculado ao então emergente campo da Nutrição, encontravam-se demarcados no projeto dos primeiros médicos nutrólogos brasileiros. Costa (1953), por exemplo, idealizador dos cursos desenvolvidos pelo SAPS para nutrólogos, nutricionistas e demais profissionais desta área, concebia os médicos nutrólogos como "especialistas na moderna Nutrologia, dotados de conhecimentos e visão bem mais amplos que os antigos 'dietetas', que sempre os ouve", enquanto "as nutricionistas" seriam as "auxiliares diretas daqueles médicos". Maurício (1964), por sua vez, representante da segunda geração de médicos nutrólogos brasileiros, permanecia argumentando que "cabe(ria) ao nutrólogo a orientação clínica e dietoterápica em relação ao enfermo, cabendo-lhe outrossim a parte médica e fisiológica da profissão em face de sua formação especializada". Ao mesmo tempo, afirmava que "o papel da nutricionista, é (era) sobretudo relevante quer como executante da prescrição médica, quer exercendo funções de auxiliar ou chefia de serviços dietéticos".

Além da criação dos primeiros cursos para formação de nutricionistas, importantes eventos desta história, ocorridos no período 1939-1949, precisam ser ressaltados. Na área da Política Social de Alimentação e Nutrição, destacam-se: 1) a 
instituição do salário mínimo, em $1^{\circ}$ de maio de 1940, o qual teve como base de cálculo o que se convencionou chamar de ração essencial mínima (ou cesta básica) e 2) a criação do Serviço de Alimentação da Previdência Social (SAPS), em 5 de agosto de 1940, instituição que se transformaria em um dos principais centros de formação de recursos humanos na área de Nutrição (nutrólogos, nutricionistas, economistas domésticas etc.), bem como em um dos principais campos de trabalho para nutricionistas (Vasconcelos, 1988).

Na área do desenvolvimento científico-tecnológico e de organização dos profissionais do campo da Nutrição, devem ser enfatizadas: 1) a fundação, em 1940, da Sociedade Brasileira de Nutrição (SBN), entidade de caráter técnico-científico e cultural que passaria a defender os interesses dos profissionais do setor, particularmente, dos médicos nutrólogos; 2) a criação dos Arquivos Brasileiros de Nutrição, em maio de 1944, primeira revista científica brasileira neste campo específico do conhecimento e 3) a fundação da Associação Brasileira de Nutricionistas (ABN), em 31 de agosto de 1949, primeira entidade brasileira criada com o intuito de representar e defender os interesses dos nutricionistas/dietistas, bem como desenvolver estudos e pesquisas no campo da Nutrição. Em função disso, a partir de então, a data 31 de agosto passou a ser comemorada como o "dia do nutricionista" (Conselho Federal..., 1999; Vasconcelos, 1999a).

Em síntese, ao final deste período, pode-se dizer que a Nutrição, enquanto campo específico do saber, atividade política da agenda do estado capitalista brasileiro e atividade profissional ou campo de trabalho, demonstrava ter sido institucionalizada e incorporada a um segmento mais amplo da sociedade brasileira.

\section{A C ONSOLIDAÇÃO (1950-1975)}

Nos anos 1950 foram criados mais dois cursos para formação de nutricionistas e no final da década de 60 existiam sete cursos no Brasil. Em 1956, por iniciativa do médico Adriano de Azevedo Pondé, foi criado o Curso de Nutricionistas da Universidade da Bahia (atual Curso de Graduação em Nutrição da Escola de Nutrição da Universidade Federal da Bahia). Em 1957, por iniciativa do médico Nelson Ferreira de Castro Chaves, foi fundado o Curso de Nutricionistas do Instituto de Fisiologia e Nutrição da Faculdade de Medicina de Recife (atual Curso de Graduação em Nutrição do Departamento de Nutrição da Universidade Federal de Pernambuco). Finalmente, em 1968, foi criado, em Niterói (RJ), o atual Curso de Graduação em Nutrição da Universidade Federal Fluminense (Brasil..., 1983; Bosi, 1988; Associação..., 1991).

A partir dos anos 1960s, de acordo com algumas análises, passou-se a discutir, no âmbito da comunidade latino-americana de Nutrição, a formação de "um profissional de nível universitário, qualificado por formação e experiência, para atuar nos Serviços de Saúde Pública com o fim de melhorar a nutrição humana, essencial para a manutenção do mais alto nível de saúde" (Ypiranga \& Gil, 1989). Segundo estas constatações, a partir de então, o processo de formação do nutricionista no Brasil, centralizado nas duas características da prática profissional (a elaboração e a orientação dietética dentro dos serviços de atenção à saúde e a administração de serviços de alimentação de trabalhadores vinculados à previdência social), começou a sofrer algumas alterações (Ypiranga \& Gil, 1989). Este fato se constituiu em um dos eventos sinalizadores do processo de instituição do campo da Nutrição em Saúde Pública dentro do contexto internacional e, particularmente, no interior dos países latino-americanos.

Outras análises, entretanto, apontam eventos bastante antecedentes como sinalizadores da emergência do campo da Nutrição em Saúde Pública. Segundo estas avaliações, no pós-Segunda Guerra Mundial, uma nova ordem político-econômica começou a ser estabelecida no plano internacional. A partir de 1946, teve início a 
chamada guerra fria entre os países capitalistas industrializados do hemisfério norte, liderados pelos EUA, e os países socialistas da Europa Oriental e da Ásia, liderados pela União das Repúblicas Socialistas Soviéticas (URSS). Neste contexto, o campo da Nutrição, o qual havia emergido, em sua escala universal, no decorrer da Primeira Guerra Mundial, encontrou os espaços institucionais adequados para a sua ampliação e consolidação. Estes espaços institucionais foram sendo ocupados no interior das organizações de caráter internacional, criadas com o intuito de administrar os conflitos desta nova ordem mundial. Assim, pode-se identificar que a emergência do campo da Nutrição em Saúde Pública, dentro do contexto internacional, ocorreu especificamente no interior de agências especializadas da Organização das Nações Unidas (ONU), tais como o United Nations International Children's Emergency Fund (UNICEF), a Food and Agriculture Organization (FAO), a Organização Mundial de Saúde (OMS) e a Organização Pan-Americana de Saúde (OPAS) (Coimbra et al., 1982; L'Abbate, 1988).

Deduz-se, portanto, que a preocupação com a questão da alimentação e nutrição da população mundial (dentro de uma abordagem do coletivo) teve início com o desenrolar da Segunda Guerra Mundial. Um primeiro indício desta preocupação foi a realização, em 1941, da National Nutrition Conference for Defense (conhecida como a Conferência de Washington), convocada pelo Presidente Roosevelt. O passo seguinte foi a realização, em 1943, da Conferência de Alimentação de Hot Spring, Virgínia, também convocada pelo presidente norte-americano, com a participação de representantes de 44 países, onde foi proposta a criação de um órgão internacional especializado em alimentação. Esta conferência de 1943 deu origem à criação, em 1946, tanto da FAO, entidade da ONU responsável pela questão da alimentação e nutrição mundial, como do UNICEF, entidade com fins humanitários de assistência às crianças européias vítimas dos efeitos da Segunda Guerra Mundial. Em 1948, em Montevidéu, no Uruguai, realizou-se a $1^{\text {a }}$ Conferência Latino-Americana da FAO, sendo este o primeiro evento científico da FAO a recomendar o desenvolvimento de atividades específicas no campo da Nutrição em Saúde Pública, dentro do contexto internacional (Castro, 1980; Coimbra et al., 1982; L'Abbate, 1988).

No caso do Brasil, a emergência do processo de institucionalização do campo da Nutrição em Saúde Pública tem sido associada à fundação, em 1957, do Curso de Nutricionistas do então Instituto de Fisiologia e Nutrição da Faculdade de Medicina de Recife, apontado por alguns estudos como o primeiro curso brasileiro a formar profissionais voltados para a atuação no campo da Nutrição em Saúde Pública. No nosso entendimento, a emergência deste campo científico, denominado de Nutrição em Saúde Pública, também reconhecido por Nutrição em Medicina Preventiva, por Nutrição Social, por Nutrição Comunitária ou, ainda, por Nutrição em Saúde Coletiva, foi um produto do processo histórico de especialização e divisão do trabalho/saber no interior da complexa e multidisciplinar ciência da Nutrição, constituída nos anos 1930-1940 no Brasil (Vasconcelos, 1999b).

Ao final deste período, além da ampliação do número de cursos, profissionais e áreas de atuação, outras importantes conquistas foram incorporadas à história do nutricionista no Brasil. Ressaltam-se, entre elas, o reconhecimento dos Cursos de Nutricionistas como de nível superior e a aprovação da lei de regulamentação da profissão.

A luta pelo reconhecimento do curso de nutricionista como de nível superior teve seu início por volta de 1952, quando não só os cursos até então existentes como também a ABN começaram a encaminhar ao Ministério da Educação os primeiros pedidos de reconhecimento. Após cerca de dez anos, através do Parecer n²65, de 19 de outubro de 1962, o então Conselho Federal de Educação (CFE) reconheceu os Cursos de Nutricionistas como de nível superior, estabeleceu o primeiro currículo mínimo e fixou a duração de 
134 | F.A.G. VASCONCELOS

três anos para a formação de nutricionistas, a nível nacional (Associação..., 1991; Conselho Federal..., 1999).

A luta pela regulamentação da profissão, por sua vez, teve seu desfecho positivo apenas em 24 de abril de 1967, quando foi sancionada a Lei $n^{\circ} 5.276$, dispondo sobre a profissão de nutricionista, regulando o seu exercício e dando outras providências - instrumento legal que vigorou até 1991, quando foi revogada por uma nova legislação (Associação..., 1991; Conselho Federal..., 1999).

\section{A EVOLUÇÃO (1976-1984)}

Na década de 1970, sobretudo a partir de 1976, com a instituição do II Programa Nacional de Alimentação e Nutrição (II PRONAN), desenvolvido sob a coordenação do então Instituto Nacional de Alimentação e Nutrição (INAN), autarquia vinculada ao Ministério da Saúde, verificou-se um acelerado processo de criação de novos cursos para formação de nutricionistas no Brasil. Neste sentido, como uma das diretrizes do II PRONAN consistia em estimular o processo de formação e capacitação de recursos humanos em Nutrição, no período de 1975 a 1981, expandiu-se, assustadoramente, de 7 para 30 o número de cursos de Nutrição existentes no país, representando um aumento de cerca de $443 \%$. Paralelamente, neste mesmo período, observou-se um expressivo aumento da oferta de vagas nestes cursos, que passou das 570 existentes em 1975, para 1592 em 1980, representando um aumento de cerca de $279 \%$ (Tabela 1). Além disso, a partir deste período teve início o processo de criação dos cursos do setor privado, os quais em 1980 correspondiam a 30\% do total existente e eram responsáveis por $48 \%$ do total de vagas oferecidas no país (Brasil..., 1983; Bosi, 1988).

A expansão do número de cursos e de nutricionistas no país, verificada neste período, por sua vez, forjou a ampliação e diversificação do mercado de trabalho, bem como o processo de organização, mobilização e luta desta categoria profissional em prol dos seus interesses e necessidades específicos. Assim, importantes eventos ocorridos nos anos 1970-1984 merecem ser destacados.

Em primeiro lugar, ressaltam-se as discussões travadas em torno do processo de formação acadêmica do profissional, das quais resultaram: 1) a fixação pelo CFE, em 1974, do segundo currículo mínimo, o qual estabelecia uma carga horária total de 2880 horas, a ser integralizada com uma duração de 4 anos e 2) a realização dos I e II Diagnósticos dos Cursos de Nutrição, realizados em 1975 e 1980, respectivamente, com objetivos de avaliar a formação do nutricionista em todo o território nacional (Brasil..., 1983; Bosi, 1988).

Em segundo lugar, destaca-se a aprovação da Lei $n^{\circ} 6.583$, de 20 de outubro de 1978 (publicada no Diário Oficial da União em 24/10/1978), a qual "cria os Conselhos Federal e Regionais de Nutricionistas, regula o seu funcionamento, e dá outras providências". Com a aprovação da referida lei, os nutricionistas brasileiros, até então sob a responsabilidade dos órgãos regionais de fiscalização da Medicina, passam a dispor de um órgão específico com a finalidade não apenas de fiscalizar o exercício da profissão, mas também de organizar, disciplinar e desenvolver a categoria e lutar pelos seus interesses (Conselho..., 1999).

Por fim, salienta-se a atuação da Federação Brasileira das Associações de Nutricionistas (FEBRAN), entidade de caráter técnico-científico e cultural, criada em 1972, que passou a assumir as funções da sua antecessora, a ABN, congregando as inúmeras associações estaduais de nutricionistas. Ainda neste período, teve início o processo de criação das associações profissionais (ou pré-sindicais), as quais deram origem aos Sindicatos de Nutricionistas em vários Estados brasileiros (Associação..., 1991).

\section{A REPRODUÇÃ O AMPLIADA $(1985-2000)$}

Nos últimos quinze anos verificou-se um processo de expansão do número de Cursos de 
Nutrição muito mais intenso do que no período anterior. De acordo com dados recentes (Calado, 2000), em 31 de janeiro de 2000 existiam 106 Cursos de Nutrição no país, sendo 22 públicos e 84 privados. Ou seja, observou-se uma expansão de cerca de $342 \%$ no número de cursos, um aumento exclusivamente determinado pela criação de 75 novos cursos privados (Tabela 1).

Tabela 1. Distribuição dos números de cursos e de vagas nos Cursos de Nutrição no Brasil nos anos de 1975, 1981 e janeiro de 2000.

\begin{tabular}{ccccc}
\hline \multirow{2}{*}{ Ano } & \multicolumn{4}{c}{ Cursos (n) } \\
\cline { 2 - 4 } & Total & Públicos & Privados & \\
\hline 1975 & 7 & 7 & - & 570 \\
1981 & 30 & 21 & 9 & 1592 \\
2000 (Janeiro) & 106 & 22 & 84 & 8000 \\
\hline
\end{tabular}

Fonte: Elaborada com base em dados contidos em Bosi (1988) e Calado (2000).

Em relação à distribuição dos 106 Cursos de Nutrição por Região e Estado do país, o estudo de Calado (2000) demonstra que, deste total, $64(60,4 \%)$ localizam-se na Região Sudeste; 23 $(21,7 \%)$, na Região Sul; 8 (7,5\%), na Região Nordeste; 8 (7,5\%), na Região Centro-Oeste; e 3 $(2,8 \%)$, na Região Norte (Figura 1). Além disso, o Estado de São Paulo lidera a relação com 42 $(39,6 \%)$ do total de cursos, seguido pelos Estados do Rio de Janeiro, Paraná e Rio Grande do Sul, os quais apresentam, respectivamente, $12(11,3 \%)$, $12(11,3 \%)$ e $9(8,5 \%)$ deste total.
Ainda de acordo com Calado (2000), a oferta de vagas na Graduação em Nutrição, em janeiro de 2000, correspondia a cerca de oito mil por ano. Por outro lado, à medida que observou-se um acelerado aumento destas vagas nos cursos privados das Regiões Sudeste, Sul, Centro-Oeste e Norte, na Região Nordeste o número permaneceu inalterado desde 1982. Levando em consideração o número existente em 1980 (1592 vagas), neste período de vinte anos, observa-se um crescimento de $502,5 \%$ ou cerca de cinco vezes maior (Bosi, 1988).

Conseqüentemente, com os acelerados aumentos do número de cursos e de vagas, nos últimos quinze anos também observou-se uma ampliação quantitativa de nutricionistas no país. Dados recentes do Conselho Federal de Nutricionistas (Conselho..., 2000) apontam um efetivo de 27834 profissionais registrados, até 30 de junho de 2000, nos sete Conselhos Regionais existentes no país. Os dez Estados brasileiros onde verificam-se as maiores concentrações de nutricionistas, em ordem decrescente, são: São Paulo com 7524 (27,0\%); Rio de Janeiro com 5117 (18,4\%); Rio Grande do Sul com 4991 (17,9\%); Bahia com 1386 (5,0\%); Paraná com 1037 (3,7\%); Distrito Federal com 1008 (3,6\%); Minas Gerais com 913 (3,3\%); Pernambuco com 872 (3,1\%); Mato Grosso com 590 (2,1\%); e Santa Catarina com 585 (2,1\%) (Tabela 2).

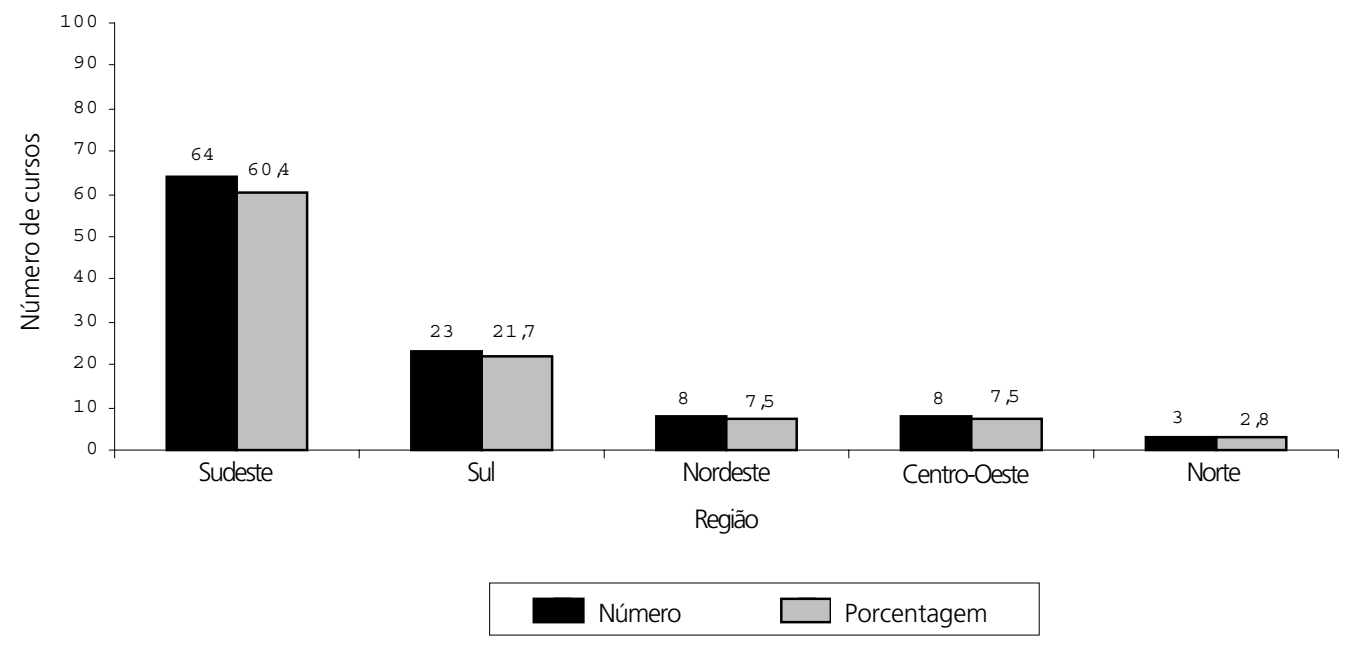

Figura 1. Distribuição dos 106 Cursos de Nutrição por Região brasileira, em janeiro de 2000. Fonte: Elaborada com base em dados contidos em Calado (2000). 
Tabela 2. Distribuição do total de nutricionistas brasileiros inscritos nos distintos Conselhos Regionais (CRNs) até 31/03/2000 por unidade da Federação.

\begin{tabular}{|c|c|c|}
\hline Estado & $\mathrm{n}$ & $\%$ \\
\hline SãoPaulo & 7524 & 27,00 \\
\hline Rio de Janeiro & 5117 & 18,40 \\
\hline Rio Grande do Sul & 4991 & 17,90 \\
\hline Bahia & 1386 & 5,00 \\
\hline Paraná & 1037 & 3,70 \\
\hline Distrito Federal & 1008 & 3,60 \\
\hline Minas Gerais & 913 & 3,30 \\
\hline Pernambuco & 872 & 3,10 \\
\hline Mato Grosso & 590 & 2,10 \\
\hline SantaCatarina & 585 & 2,10 \\
\hline Ceará & 562 & 2,00 \\
\hline Goiás & 513 & 1,80 \\
\hline Pará & 455 & 1,60 \\
\hline Rio Grande do Norte & 391 & 1,40 \\
\hline Alagoas & 326 & 1,20 \\
\hline Paraíba & 310 & 1,10 \\
\hline Piauí & 304 & 1,10 \\
\hline Espírito Santo & 173 & 0,60 \\
\hline Mato Grosso do Sul & 93 & 0,30 \\
\hline Maranhão & 89 & 0,30 \\
\hline Amazonas & 79 & 0,30 \\
\hline Sergipe & 73 & 0,30 \\
\hline Amapá & 39 & 0,10 \\
\hline Rondônia & 31 & 0,10 \\
\hline Tocantins & 26 & 0,10 \\
\hline Acre & 18 & 0,05 \\
\hline Roraima & 17 & 0,05 \\
\hline Outros (CRN-6 e CRN-4) & 312 & 1,10 \\
\hline Total & 27834 & 100,00 \\
\hline
\end{tabular}

Fonte: Elaborada com base em dados contidos em Conselho Federal de Nutricionistas (2000)

Além destes fatos, outros eventos importantes, ocorridos nos anos 1985-2000, merecem ser destacados, entre eles, o crescente processo de mobilização e politização da categoria, que resultou na realização de importantes eventos técnico-científicos e sindicais e na criação da Associação Brasileira de Nutrição (ASBRAN), em 8 de junho de 1990, em substituição à FEBRAN, e, por fim, a aprovação da Lei ${ }^{\circ} 8234$, de 17 de setembro de 1991 (publicada no Diário Oficial da União de 18 de setembro de 1991), a qual "regulamenta a profissão de nutricionista e determina outras providências", revogando inclusive sua antecessora a Lei $n^{\circ}$ 5276/1967 (Associação..., 1991; Conselho Federal..., 1999).

\section{CONSIDERACÕES FINAIS}

Há cerca de sessenta anos emergia no Brasil a profissão de nutricionista. Àquela época, frente à tortuosa tarefa de construção da nacionalidade brasileira e de implantação das bases para a consolidação de uma sociedade capitalista urbano-industrial, o principal desafio que se colocava a este profissional era a superação do perfil epidemiológico nutricional daquele contexto, caracterizado sobretudo pelas doenças carenciais (desnutrição protéico-calórica, hipovitaminose A, pelagra, anemia ferropriva, etc.), associadas às condições de "subdesenvolvimento", de pobreza, de fome, de desigualdades regionais. Nos dias atuais, àquele perfil epidemiológico sobrepuseram-se as doenças nutricionais degenerativas (obesidade, diabetes, dislipidemias, etc.), associadas às condições de "desenvolvimento" e de "modernidade" existentes no país e, assim, novos dilemas e desafios são apresentados aos nutricionistas.

Neste novo cenário, torna-se fácil reconhecer o grande paradoxo do processo de modernização brasileira: o desenvolvimento econômico conquistado ao longo dos últimos 60 anos, o qual coloca o país no ranking das dez grandes potências econômicas mundiais, permite que apenas uma pequena parte da população possa situar-se na esfera de consumo e reprodução material das sociedades mais desenvolvidas do mundo, enquanto uma significativa parcela permanece condenada às mais degradantes condições de reprodução e de existência humana.

No seio destas contradições que levaram milhões de brasileiros a um intenso processo de exclusão social, nas duas últimas décadas, o povo é "bombardeado" diariamente com cenas de barbárie, de corrupção, de extrema violência e de irracionalidade, as quais poderiam prenunciar um cenário de "caos" para este início do terceiro milênio. Por outro lado, nos últimos anos, também assistimos ao desenrolar dos movimentos 
ecológico, bioético, da "Ação da Cidadania contra a Fome, a Miséria e pela Vida" e tantos outros, cujos objetivos são a construção de novos paradigmas, de resgate e/ou adoção de novos valores humanos, de preocupação com a qualidade de vida e o estabelecimento de novas relações entre os homens e entre homens-natureza, onde os princípios da igualdade fundamental de direito e de co-responsabilidade de todos os indivíduos possam prevalecer. É, portanto, no interior destes últimos movimentos que se espera poderem assentar-se as perspectivas imediatas e mediatas desta prática profissional.

Os avanços quantitativos e qualitativos conquistados pela categoria ao longo destas seis primeiras décadas de mobilização, organização e luta em busca de legitimidade, autonomia e identidade profissional são evidentes e, ao que tudo indica, irreversíveis. Dentre estas conquistas pode-se destacar a sensível ampliação dos campos de atuação profissional, fato gerador de um crescente processo de especialização/divisão do objeto de trabalho/estudo do nutricionista e, conseqüentemente, de uma melhor qualificação das suas habilidades e competências técnico- científicas. Por outro lado, em tempos de globalização, a incorporação dos avanços científico-tecnológicos oriundos principalmente da Informática e Computação, bem como da indústria de máquinas e equipamentos, imporá a construção de um novo perfil profissional. Apesar da tendência à unificação (ou uniformização) dos hábitos e padrões alimentares que o processo de globalização econômica parece desencadear, também se observa uma crescente preocupação/ conscientização com o resgate e a preservação da "cultura dietética" nacional, com o controle de qualidade e com a segurança alimentar. Ou seja, a incorporação de novos valores e princípios oriundos de outros campos disciplinares, sem dúvida, propiciará a síntese de uma nova Nutrição no século $X X I$, o que poderá contribuir para a superação do paradoxo nutricional brasileiro (desnutrição versus obesidade).

\section{REFERENCIAS BIBLIOGRÁFICAS}

ASSOCIAÇÃO BRASILEIRA DE NUTRIÇÃO. Histórico do nutricionista no Brasil - 1939 a 1989: coletânea de depoimentos e documentos. São Paulo: Atheneu, 1991. 444p.

BOSI, M.L.M. A face oculta da nutrição: ciência e ideologia. Rio de Janeiro : Espaço e Tempo, 1988. 220p.

BRASIL. Ministério da Educação e Cultura. Secretaria de Ensino Superior. Os cursos de nutrição no Brasil: evolução, corpo docente e currículo. Braślia, 1983. 280p. (Série de Cadernos de Ciências da Saúde, 6).

CALADO, C.L.A. A nova LDB e o curso de nutrição. Jornal do CFN, Brasília, v.2, n.6, p.5, abr. 2000.

CASTRO, J. Geografia da fome: o dilema brasileiro: pão ou aço. 10.ed. rev. Rio de Janeiro : Antares, 1980. $361 \mathrm{p}$.

COIMBRA, M., MEIRA, J.F.P., STARLING, M.B.L. Comer e aprender: uma história da alimentação escolar no Brasil. Belo Horizonte : MEC/INAE, 1982. 685p.

CONSELHO FEDERAL DE NUTRICIONISTAS. Histórico do CFN. Jornal do CFN, Brasília, v.1, n.4, p.2-4, ago. 1999. (Encarte Comemorativo).

CONSELHO FEDERAL DE NUTRICIONISTAS. Quadro estatístico do $2^{\circ}$ trimestre/2000 (1\%04/2000 a 30/ 06/2000) [online]. Disponível em: <http:// www.cfn.org.br/variavel/destaque/ quadro_estatistico.htm> Acesso em: 24 nov. 2000.

COSTA, D. A importância do ensino da nutrição: o seu desenvolvimento no Brasil. Revista Brasileira de Medicina, Rio de Janeiro, v.10, n.9, p.645-650, 1953.

FREYRE, G. Casa-grande \& senzala. 34.ed. Rio de Janeiro : Record, 1998. 569p.

ICAZA, S.J. Evolución histórica de la formación del nutricionista-dietista en américa latina. In: REUNIÓN DE COMISIÓN DE ESTUDIOS SOBRE PROGRAMAS ACADÉMICOS EN NUTRICIÓN Y DIETÉTICA DE AMÉRICA LATINA, 4., 1991, San Juan, Puerto Rico. Memória... San Juan, Puerto Rico : OPAS, 1991. p.51-62. 
L'ABBATE, S. As políticas de alimentação e nutrição no Brasil: I. Período de 1940 a 1964. Revista de Nutrição da PUCCAMP, Campinas, v.1, n.2, p.87-138, 1988.

LIMA, E.S. Gênese e constituição da educação alimentar: a instauração da norma. São Paulo, 1997. 407p. Tese (Doutorado em Educação) - Pontifícia Universidade Católica de São Paulo, 1997.

MAGALHÃES, R. Fome: uma (re)leitura de Josué de Castro. Rio de Janeiro : Fiocruz, 1997. 87p.

MARTINS, J.T. A biologia no Brasil. In: AZEVEDO, F. (Org.). As ciências no Brasil. 2.ed. Rio de Janeiro : UFRJ, 1994. v.2, p.233-300.

MAURíCIO, H.V. Evolução da nutrição e do seu ensino no Brasil. Arquivos Brasileiros de Nutrição, Rio de Janeiro, v.20, n.2, p.117-134, 1964.

VASCONCELOS, F.A.G. A política social de alimentação e nutrição no Brasil: acumulação de capital e reprodução da fome/desnutrição: do Estado Novo à Nova República. João Pessoa, 1988. 207p. Dissertação (Mestrado em Serviço Social) - Depar- tamento de Serviço Social, Centro de Ciências Humanas, Letras e Artes, Universidade Federal da Paraíba, 1988.

VASCONCELOS, F.A.G. Os Arquivos Brasileiros de Nutrição: uma revisão sobre produção científica em nutrição no Brasil: 1944 a 1968. Cadernos de Saúde Pública, Rio de Janeiro, v.15, n.2, p.303-316, 1999a.

VASCONCELOS, F.A.G. Como nasceram os meus anjos brancos: a constituição do campo da nutrição em saúde pública no Brasil. Rio de Janeiro, 1999. 266p. Tese (Doutorado em Saúde Pública) - Escola Nacional de Saúde Pública, Fundação Oswaldo Cruz, 1999b.

YPIRANGA, L., GIL, M.F. Formação profissional do nutricionista: por que mudar? In: CUNHA, D.T.O., YPIRANGA, L., GIL, M.F. (Org.). I/ Seminário Nacional sobre o Ensino de Nutrição. Goiânia : FEBRAN, 1989. p.20-36.

Recebido para publicação em 18 de dezembro de 2000 e aceito em 7 de agosto de 2001. 